\title{
Management of adult sex offenders
}

\section{Josanne Holloway}

The true incidence and prevalence of sexual abuse against children is difficult to ascertain. Differing sampling methods, definitions of sexual abuse and methods of information-gathering have a significant effect on the rates reported. General population studies (Morrison et al, 1994) in the USA and Europe reveal a rate between 0.7 and 1.83 per 1000 children. Data from prevalence studies (Morrison et al, 1994) highlight large differences, with rates varying from 7 to $62 \%$; meanwhile, only between 2 and $17 \%$ of sexual assaults are reported to the police. Many of the reported offenders are not prosecuted because of difficulties with the child's statement. Some offenders are cautioned, others are charged with specimen charges or have their charges downgraded. Despite an increase in the reporting of sexual offences since the 1970s, they account for only approximately $3 \%$ of all offenders on probation and $8 \%$ of male offenders in prison even though the number and length of prison sentences for sex offenders has increased since the 1970s. Convicted female offenders remain a very small group with only 23 convicted female sex offenders in custody in 1989.

A multi-disciplinary, multi-agency approach in the management of offenders and the protection of victims is essential given the difficulties encountered in managing adult sex offenders and the complexity and diversity of the various systems in operation. Enquiries into the management of mentally disordered offenders (Sheppard, 1996) and the review on health and social services for mentally disordered offenders (Reed Report, Department of Health \& Home Office, 1992) have highlighted the need for close and effective multi-agency working for effective care of the individual and protection of the public.

\section{Identification}

Multi-agency involvement with sex offenders, particularly offenders against children, occurs early once abuse comes to light and involves the police, social services and the National Society for the Prevention of Cruelty to Children. The police are involved in investigating the behaviour, and later have a role in the multi-agency risk panels monitoring high-risk offenders on release from custody. The Crown Prosecution Service (CPS) is involved once charges are to be brought. Probation services are involved early if the offender has pleaded guilty to at least one of the charges put to him. A field probation officer working with specialist probation officers jointly interview offenders and provide the social enquiry reports to advise the court on sentencing options. If the offender pleads not guilty, but is later found guilty, probation services provide a report at this later stage. The sentencing options available to the court usually include an element of 'treatment'.

The stage at which a psychiatrist or psychologist gets involved in the management of a sex offender is arbitrary and dependent on the offender referring himself for help or on referral by other agencies. It is very rare for anyone with paedophile tendencies to present himself for help before their behaviour has come to notice or before they have sexually abused a child.

Psychiatrists, psychologists and other therapists can first become aware of a sexual offender when asked to prepare psychiatric reports by the defendnt's solicitor or the courts. It is important to be aware that one can sometimes inadvertently provide information that the offender has not divulged or admitted to anybody else. It is therefore essential that defendants are told that the clinical relationship between themselves and the psychiatrist is different to the usual doctorpatient relationship and that information given during the session(s) is not covered by the usual rules of confidentiality.

The General Medical Council, British Medical Association and defence unions have all issued guidance (Home Office et al, 1991) on breaching confidential information. The Annual report of the General Medical Council (1991) states that : 
"if a doctor has reason for believing that a child is being physically or sexually abused, not only is it permissible for the doctor to disclose information to a third party but it is the duty of the doctor to do so".

\section{Assessment}

Assessment of sexual offenders is complex. It has been suggested ( $\mathrm{O}^{\prime}$ Connell et al, 1990) that careful selection of therapists is required, taking into account clinical experience, specialised knowledge and personal skills in order to elicit more accurate and relevant information, to be less susceptible to manipulation and to be aware of the relevance of the offender's behaviour during the assessment.

Self-reporting by the offender is affected by their tendency to distort, deny or minimise their offences and justify their behaviour. The clinical interview therefore needs to be supported by other information including depositions, police summaries, probation reports, relevant questionnaires and any other documentation including child care case conference minutes. Close liaison with other agencies involved is an essential part of the assessment process.

Assessment of sexual offenders should be multidisciplinary and include an evaluation of the risk of further offending, identification of appropriate treatment strategies and, later, an evaluation of treatment effectiveness and monitoring of treatment gains. A multi-factorial model looking at internal motivators, external motivators, disinhibiting factors, protecting factors and vulnerability factors within the child victims is needed to understand the sexual behaviour and offending pattern of the perpetrator.

\section{The medical report}

The court, when sentencing an offender, is not only interested in his welfare but is also concerned with protecting the public from the defendents criminal behaviour. A medical report should include information to help the court assess the offender's culpability/responsibility; to help the court pass a sentence designed to stop the person from offending again; and to help the court to pass a sentence to protect society from the offender (Box 1). It is therefore important for the psychiatrist during the assessment, to identify the defendant's problems and consider and report on any psychiatric or psychological conditions that may affect the person's responsibility. The psychiatrist must also identify any treatment options which may effect these and
Box 1. The medical report helps the court to:

Assess the offender's culpability/responsibility

Pass a sentence designed to stop the person offending again

Pass a sentence to protect society from the offender

provide the court with a framework for their implementation, including where they can be implemented, for example in the community, hospital or in prison, and look at the prognosis for the individual, including the time required for progress to be made and how this will be monitored.

\section{Court process}

\section{The Crown Prosecution Service}

The CPS is involved in agreeing the charges to be brought and may decide to charge the offender with a less serious offence. This may occur when the more serious charge is difficult to prove, or if the offender agrees to plead guilty to a lesser charge, thus avoiding the need for the victim to give evidence in court and the need for a trial. This acknowledgement of guilt by the offender (only partial acknowledgement, if he is pleading guilty to a lesser charge) can significantly affect the offender's functioning in the therapeutic process. Clinicians working therapeutically with the offender need to be aware of the process by which an offender's charges have been brought, in order that relevant therapeutic issues can be addressed effectively. The CPS is usually willing to discuss with clinicians the role that treatment may play in sentencing.

\section{Criminal Justice Act 1991}

The Criminal Justice Act 1991 makes special provisions for offenders convicted of a violent or sexual offence (Box 2). An offender convicted of a sexual offence can be given a custodial sentence, if this is the only sentence that will protect the public from serious harm from him. He can also be given a longer sentence than would be otherwise permitted, if this is necessary to protect the public from serious harm. The court can extend the licence of a person convicted of a sexual offence, if it is considered desirable in order to protect the public from serious harm, to prevent the commission of further offences 
Box 2. Provisions for sexual offences within the Criminal Justice Act 1991

Pass a custodial sentence, if this is the only sentence that will protect the public

Pass a longer sentence than permitted to protect the public from serious harm

Extend the licence of a convicted person to (a) protect the public from serious harm, (b) prevent commission of further offences, (c) secure rehabilitation

and to secure rehabilitation. Psychiatrists preparing a medical report which is to be helpful to the court need, therefore, to be aware of the sentences available to the court and the requirements that must be satisfied for the various sentencing options.

Offenders convicted of a sexual offence against a child can be treated in the community as part of a community sentence (Box 3 ). A community sentence can be imposed if the court is of the opinion that the offence, or combination of the offence and one other offence associated with it, was serious enough to warrant such a sentence (rather than a financial penalty alone). When imposing a community sentence the court must be satisfied that the particular order is the most suitable for the offender. The restrictions on liberty must be commensurate with the seriousness of the offence or offences, taking into account any aggravating or mitigating circumstances, but not previous convictions or sentences.

Conditions of residence, attendance for specified activities, attendance at a probation centre, treatment for a medical condition and treatment for drug or alcohol dependence are sometimes added to community sentences. When a condition for medical treatment is included, the order must specify that the treatment is as: (a) a resident in a hospital (though not a special hospital) or a nursing home; (b) as a non-resident, that is, an out-patient at a hospital; or (c) whether it is under the direction of a named

Box 3. Community sentences: Criminal Justice Act 1991

\section{Probation}

Community service

Combination order (probation and community service)

Curfew order

Supervision order (for offenders under the age of 18 only)

Attendance order (for offenders under the age of 21 only). psychiatrist. The requirement to attend for specific activities may be to take part in group therapy for their sexual offending. All these community sentences are supervised by probation services. The psychiatrist's role is that of therapist, though most community treatment schemes ensure that the offenders taking part in any therapeutic activity as part of a community sentence agree that some information including record of attendance is regularly conveyed to the supervising probation officer who can, if the offender is not cooperating with treatment, choose to return the offender to court for breach of his probation order. The court then has the option of re-sentencing the offender for the original offences and for the offence of breaching his probation order.

It is for the probation officer, not the psychiatrist, to recommend a probation order or other community sentence. However, it is good practice for the psychiatrist writing a report to discuss any case with the probation officer involved and, if appropriate, support the probation officer's recommendation of a community sentence.

The Crime (Sentences) Act 1997 abolishes the requirement that an offender consents to a community sentence (except for an attendance order) proposed by the court. However, consent is still required if a condition of treatment for a mental condition or drug or alcohol dependency is attached to a community order.

\section{Crime (Sentences) Act 1997}

Most of the new Crime (Sentences) Act was brought into force on 1 October 1997. Part 1 of the act deals with mandatory life sentences. Section 2 requires the court to impose a sentence of life imprisonment on a person who is convicted of a second serious offence if he was 18 or over at the time of the offence unless the court is of the opinion that there are special circumstances relating either to the offences or the offender. The sexual offences covered are rape, attempted rape and sexual intercourse with a girl under 13 years of age. Mental disorder (including mental illness) is specifically excluded as a special circumstance and a hospital order under Section 37 of the Mental Health Act 1983 cannot be imposed as an alternative to life imprisonment. For people with a psychopathic disorder, however, a hospital direction under the Mental Health Act can be imposed.

\section{Mental Health Act 1983}

Most sexual offenders are not mentally ill and do not require in-patient hospital care. However, 
some offenders may suffer from other forms of mental disorder defined in the Mental Health Act 1983. Psychiatrists differ on how best to deal with the category of psychopathic disorder. (This category is excluded from Scottish mental health legislation.) Section 46 of the Crime (Sentences) Act 1997 introduces new sections (45A and 45B) to the Mental Health Act 1983 (see Box 4) enabling the Crown Court to attach a hospital direction when imposing a sentence of imprisonment to a mentally disordered offender except where the sentence is fixed by law, such as when the conviction is for murder. Discussion among forensic psychiatrists at recent meetings of the Section of Forensic Psychiatry of the Royal College of Psychiatrists had suggested that such an order may encourage psychiatrists to attempt therapeutic intervention with offenders who fulfil the criteria for psychopathic disorder. The offender

Box 4. Hospital direction (Mental Health Act 1983 Sections 45A and 45B)

The hospital direction is available in respect to all sentences passed in the higher court including the life sentences passed under Section 2 of this act but excluding those fixed by law (i.e. for convictions of murder)

The hospital direction may be made if the court is satisfied on the evidence of two registered medical practitioners, at least one of whom has given evidence orally before the court that: (a) the offender is suffering from psychopathic disorder and (b) the disorder is of a nature or degree which makes it appropriate for him to be detained in hospital for treatment and (c) that such treatment is likely to alleviate or prevent a deterioration of his condition.

Offenders must be admitted within 28 days of the direction to a hospital named in the direction; once there the offender will be managed as though transferred under Section 47 of the Mental Health Act 1983 with a restriction direction.

The offender may serve his entire sentence in hospital if the responsible medical officer is satisfied that he is benefiting from treatment but transfer back to prison will be considered by the Home Secretary on receipt of medical evidence that the patient no longer requires treatment in hospital or that no further effective treatment can be given in hospital. may serve their entire sentence in hospital if the responsible medical officer is satisfied the offender is benefiting from treatment. Transfer back to prison will be possible if he no longer requires treatment in hospital or if no further effective treatment can be given in hospital. This change in legislation may result in an increase in the number of paedophile offenders being transferred to hospital for treatment.

\section{Treatment}

There are a variety of treatment approaches in this field. Cognitive-behavioural therapy with relapse prevention is currently the most prevalent. Treatment can take place in the community or inside institutions (such as prisons, special hospitals and specialist residential units). Treatment is usually in the form of group therapy, with most community programmes focusing on relapse prevention. Individual therapy and medication to reduce sexual drive sometimes supplement this. Most community treatment programmes (Thornton \& Hogue, 1993) are for child molesters. However, prison programmes treat rapists alongside paedophile offenders. All treatment programmes draw on therapists from a wide variety of professional backgrounds.

There is much debate on the effectiveness of treatment. Most outcome reviews highlight methodological flaws of the research undertaken (Quinsey, 1993; Marshall, 1993; Marshall \& Pithers, 1994), though some studies do suggest that therapeutic intervention can reduce or delay re-offending.

The National Association for the Development of Work with Sex Offenders, is an organisation drawing together many practitioners working with sex offenders, plays a key role in disseminating good practice among the different professionals working in the field.

The courts, when dealing with sex offenders, are usually willing to consider any therapeutic interventions suggested by psychiatrists, psychologists and the probation service if these are realistic, take into account public safety, address behaviour leading to the offence and may result in a reduced risk of offending. The court usually expect some degree of compulsion on the part of the offender to attend such therapeutic sessions, especially when offences are deemed to be 'of a serious nature'.

Probation officers play a major role in the management of sex offenders. In most regions, probation services have taken the lead role in 
organising and coordinating treatment groups in the community. Different areas of the country tend to have different arrangements for multidisciplinary working within this field.

The prison service runs a large-scale programme for the treatment of sex offenders using standard programme components and continued monitoring and clinical evaluation (Thornton \& Hogue, 1993). Therapists are drawn from the prison psychology service, prison officers and prison-based probation officers.

Most therapeutic intervention by psychiatrists with sexual offenders occurs on an out-patient basis, though some serious offenders are admitted to a secure hospital. It is anticipated that the changes in legislation allowing a hospital direction may result in an increase in admissions.

The role of the psychiatrist is not only to be concerned directly with the offender and his offence, but also to manage and treat other difficulties the offender may have including education, anxiety reduction, treatment of any mental illness present, and address heightened sexual drive if this is relevant. Public education is another useful role for the psychiatrist.

Psychiatrists may be involved in the management of offenders while in custody or on their release. Many prisons have regular visiting psychiatrists who see sexual offenders as part of their prison psychiatric practice but are not usually involved in therapeutic intervention. Psychiatrists may provide medical reports to the parole board. It is important to liaise with the probation service who will be providing after-care for the offender, and with any other therapist who may be involved in the community, to ensure that management of the offender is coordinated on his release into the community.

There are a number of residential settings aiming to provide intensive therapeutic interventions with paedophile offenders whose offences are unlikely to be dealt with by a probation order.

\section{Supervision}

The Home Office $(1975,1978,1994)$ has issued circulars giving guidance on liaison between the prison authorities and local authority social services departments in the case of release from custody of persons convicted of sexual offences. The most recent circular issued in 1994 links in with the Criminal Justice Act 1991 and with an earlier document (Home Office et al, 1991) giving guidance on interagency cooperation in child protection. The new
Box 5. Schedule 1 offences cover all offences committed against children and include:

Common law offences (includes murder and battery)

Person Act 1861 (includes manslaughter and abandonment)

Infant Life (Preservation) Act 1929

Children and Young Person Act 1933 (includes cruelty, allowing a person under 16 to be in a brothel)

Infanticide Act 1938

Sexual Offences Act 1956 (includes rape, procurement, unlawful sexual intercourse, incest, indecent assault, buggery, abduction)

Indecency with Children Act 1960

Suicide Act 1961

arrangements cover all offences listed in Schedule 1 of the Children and Young Person Act 1933 ('schedule 1 offences' include all offences against children; see Box 5) and increase the age limit of offences against children and young persons to include 17-year-olds.

The arrangements (HM Prison Service, 1994) require the prison service to notify and / or consult with the local social services department and the probation service at the start of custody, during custody (if there is likely to be home leave or temporary release), and towards the end of the prisoners period of custody to ensure that social services and /or the probation service may take any steps needed to protect children in the light of the release of a particular offender into the community.

Offenders who have received a term of imprisonment of between 12 months and four years are subject to automatic conditional release at the half-way point of their sentence. Offenders on longer sentences are eligible for discretionary conditional release between the half- and twothirds point of their sentence, at which stage they are subject to automatic conditional release. The conditions laid down as part of discretionary conditional releases by the parole board are based on the community supervising officer's report and, if appropriate, other reports that may include a psychiatric report. The parole board has access to all papers relevant in the case including any original psychiatric reports presented in court. Breaches of conditions (which may include conditions of residence and attendance for treatment) will either result in a court hearing for automatic conditional releases or recall to prison for discretionary conditional release. 
A psychiatrist may also be a member of the multi-agency risk panels coordinated by the probation service who look at 'high risk' offenders. Prior to release from custody, the probation officer responsible for the after-care of the offender may call a multi-agency risk panel meeting, inviting all the professionals who have had previous involvement with the offender and who may be involved in the management of the offender on release. Professionals invited may include the psychiatrist, the original investigating police officers and social workers who may have been involved. The aim of the meeting is to share information and expertise, to assess any risk of harm by the offender and to organise coordinated after-care.

\section{Sex Offender Act 1997}

The Sex Offender Act of 1997 requires that sex offenders notify the police of their name/names (and any subsequent changes), their home address (and any subsequent changes) and date of birth by:

\begin{abstract}
"attending at any police station in his local police area and giving oral notification to any police officer, or any person authorised for the purpose by the officer in charge of the station or by sending a written notification to any such police station." Sex Offender Act 1997, 2(5).
\end{abstract}

The Act is not retrospective. It covers all people who from the 1 September 1997 have been cautioned, convicted or been found not guilty by reason of insanity of a sexual offence, or who have been found unfit to plead to a sexual offence. It also includes all offenders serving a prison sentence, all offenders subject to a community order or to supervision following a prison sentence, all offenders detained in hospital following a conviction for a sexual offence or currently in hospital having been found not guilty by reason of insanity or having been unfit to plead to the charge of a sexual offence. Persons who fail to notify the police within the specified time frame are liable to a fine or to imprisonment for a term of up to six months. The aim of this act is to help in the supervision of offenders by the police service. It is not yet clear how police will choose to assess risk or how this information can be used by other professionals involved in the management of sexual offenders in the community.

The Sex Offender Act 1997 bears similarities to the requirements to register persons convicted of crimes against minors and violent sexual offences in the USA through the Violent Crime Control and Law Enforcement Act of 1994 (Lieb et al, 1994). There are differences in the type of offences and the information required by different states. All, however, require the maintenance of a register overseen by a state agency. The local police is usually responsible for collecting information and most states rely upon the offenders to notify authorities of a new address. Typically, information held on the offender includes: name, address, date of birth, finger prints, photograph, identification number, criminal record, place of employment, vehicle registration and, in some states, DNA samples.

The national DNA database came into operation in England and Wales on 10 April 1995. The Criminal Evidence (Amendment) Act 1997 enables the police to take non-intimate samples without consent for DNA profiling purposes from all prisoners in custody and patients in hospital who were convicted of certain offences (including sexual offences), or found unfit to plead or not guilty by reason of insanity prior to 10 April 1995 (Home Office, 1997b).

\section{Crime and Disorder Bill}

The Government has issued a consultation paper (Home Office, 1997a) looking at protecting the public from sex offenders and intends to bring in measures through the Crime and Disorder Bill to provide post-release supervision of sex offenders.

It is proposed that the police will have the power to seek a community protection order if a sexual offender is deemed to pose a current risk to the community. This order would be available against people who have been convicted or cautioned for a qualifying offence. It is anticipated that offences in the Sex Offenders Act 1997 would qualify. Convictions or cautions pre-dating the order, as well as convictions obtained abroad, would qualify to trigger the process. The court would need evidence of current risk before making out an order and would take into account the views of expert witnesses who may include psychiatrists, probation officers, housing officers and social workers as well as previous convictions (including cautions).

It is anticipated that the community protection order will be a civil order and offenders will be subject to the provisions of the Sex Offender Act 1997 for as long as the order is in force. The order would not impose any obligations for supervision by the probation service, though voluntary supervision would be encouraged. The court would be able to impose prohibitory requirements to protect the community from serious harm caused by the offender's sexual behaviour. The order would run for a minimum of five years. A maximum penalty of five years' imprisonment and /or an unlimited fine could be imposed for any breaches. It is proposed that the defendant would have a right of appeal against the order. 


\section{Multi-agency working}

Though it is useful for one agency to take on the lead organisational role within a cooperative structure, professionals need to retain autonomy of practice. Psychiatrists must be able to treat people within a peer-established therapeutic and ethical framework. Such autonomy of practice can cause conflict if some professionals are not allowed the same degree of professional autonomy as others. It is important to utilise the different traditions and expertise within the different professional groups. It is helpful to remain aware that within joint or multi-disciplinary working, the emphasis should be that it is multi-disciplinary, not multi-person, with professionals remaining conscious of their own and each others' expertise, training and professional role. Multi-agency working should be practical and not administrative in nature, encourage differing perspectives and techniques, be tolerant of each agency's inadequacies and restrictions and encourage learning and a widening of each agency's experience in the setting of mutual trust and respect.

In multi-agency working all professionals have differing responsibilities and roles in the management of the offender. Confidentiality and the sharing of information among the different agencies should be addressed early within a clearly defined context and forum, otherwise it causes difficulties in the assessment and therapeutic stages.

Differing styles of management within agencies can also lead to inter-agency conflict. In the health services arena, particularly among doctors, clinicians remain clinically active as well as having managerial control or responsibility for the offender in treatment. This is not the case for other professionals and difficulties can arise because of the need for managerial supervision by other professionals and the level of disclosure of clinical material to managers.

The psychiatrist's role is that of therapist and not supervisor, even though we need to be aware of the context in which therapy is taking place and the potential risk of harm to others. Psychiatrists should not be seen as an arm of the criminal justice system and in this respect we have more clinical freedom than some of our colleagues.

Working therapeutically within the context of the criminal justice system itself raises conflict. Though all professionals work to a common aim of protection of victims, other aims may not be so clearly in tune with each other. Areas of potential conflict are: punishment versus treatment, the care system versus the criminal justice system, protection of the public and sharing of information versus confidentiality and individual freedom. These need actively to be addressed and resolved to enhance the service provided to victims and offenders, otherwise they will hinder effective joint working.

Working with sex offenders is highly specialised. Professionals working in this field should not work in isolation from other professional colleagues. Public concern and government interest suggests that crime in general and sex offenders in particular will remain a government priority and a topic much discussed in the press. There has been a spate of new legislation dealing with sex offenders and the new Crime and Disorder Bill, due to be published in 1998, will bring more legislation into this field. All professionals working with sex offenders need to be aware of the current legal framework within which they work and any new proposals that may affect this.

\section{References}

Department of Health \& Home Office (1992) Review of Health and Social Services for Mentally Disordered Offenders and Others requiring Similar Services. London: HMSO.

General Medical Council (1991) Annual Report of the General Medical Council. London: GMC.

HM Prison Service (1994) Release of Prisoners convicted of Offences Against Children and Young Persons Under the age of 18 (Guidance Notes to: Instructions to Governors 54/1994). London: HM Prison Service

Home Office (1997a) Community Protection Order: A Consultation Paper. London: HMSO.

- (1997b) Police immigration service liason. (HC 12 (97)). London: Home Office.

- Department of Health, Department of Education and Science \& Welsh Office (1991) Working Together Under the Children Act 1989. A Guide to Arrangements for Inter-Agency Co-operation for the Protection of Children from Abuse. London: HMSO.

Quinsey, V. L., Harris, G. T., Rice, M. E. et al (1993) Assessing Treatment Efficacy in Outcome Studies of Sex Offenders. Journal of Interpersonal Violence, 8, 512-523.

Lieb, R. Felver, B. \& Poole, C. (1994) Sex Offender Registration: A Review of State Laws. Olympia, WA: Community Protection Research Project.

Marshall,W. L. (1993) The treatment of sex offenders: What does the outcome data tell us? A reply to Quinsey, Harris, Rice \& Lalumiere. Journal of Interpersonal Violence, 8, 524-530.

- \& Pithers, W. D. (1994)A reconsideration of treatment outcome with sex offenders. Criminal Justice and Behaviour, 21, 1027.

Morrison, T., Erooga, M. \& Beckett, R. (1994) Sexual Offending Against Children: Assessment and Treatment of Male Abusers. London: Routledge

O'Connell, M. A., Leberg, E. \& Donaldson, C. R. (1990) Working with Sex Offenders: Guidelines for Therapist Selection. London: Sage Publications.

Thornton, D. \& Hogue, T. (1993) The large-scale provision of programmes for imprisoned sex offenders: issues, dilemmas and progress. Criminal Behaviour and Mental Health, 3, 371-380.

Shepphard, D. (1996) Learning the Lessons (2nd edn). London: The Zito Trust. 